\title{
Correction to: A Quantum-like Representation of the Psychosomatic Unity
}

\section{Correction to:}

Chapter 4 in: P. Uzan, Mind-Body Entanglement, SpringerBriefs in Philosophy, https://doi.org/10.1007/978-3-030-90173-8_4

Owing to a typographical error on page 80 , the formula in the section 4.3 .1 has been presented wrongly as:

$$
\text { (Df) } \mathrm{R}=\mathrm{S}(\mathrm{aa},)+\mathrm{S}(\mathrm{ab},)+\mathrm{S}(\mathrm{b} \cdot \mathrm{a},)-\mathrm{S}(\mathrm{bb},)
$$

where $S($ aa $)$

The formula has now been updated to

$$
(D f) R=S\left(a a^{\prime}\right)+S\left(a b^{\prime}\right)+S\left(b a^{\prime}\right)-S\left(b b^{\prime}\right),
$$

where S (aa') 